\title{
Discrepancy of biologic behavior influenced by bone marrow derived cells in lung cancer
}

\author{
JIE ZHANG ${ }^{1,2^{*}}$, XIAO-MIN NIU ${ }^{3 *}$, MEI-LIN LIAO ${ }^{3}$, YUN LIU $^{4}$, HUI-FANG SHA ${ }^{3}$, \\ YI ZHAO $^{3}$, YONG-FENG YU ${ }^{3}$, QIANG TAN ${ }^{3}$, JIA-QING XIANG ${ }^{1,2}$, JING FANG $^{4}$, \\ DAN-DAN LV ${ }^{4}$, XUE-BING LI ${ }^{4}$, SHUN LU $^{3}$ and HAI-QUAN CHEN ${ }^{1,2}$
}

\begin{abstract}
${ }^{1}$ Department of Thoracic Surgery, Shanghai Cancer Hospital, ${ }^{2}$ Department of Oncology, Shanghai Medical College, Fudan University, Shanghai 200032; ${ }^{3}$ Shanghai Lung Cancer Center, Shanghai Chest Hospital, Jiao Tong University, Shanghai 200030; ${ }^{4}$ Institute for Nutritional Sciences, Chinese Academy of Sciences, Shanghai 200031, P.R. China
\end{abstract}

Received July 14, 2009; Accepted August 14, 2009

DOI: 10.3892/or_00000971

\begin{abstract}
Disseminated cancer cells may initially require local nutrients and growth factors to thrive and survive in bone marrow. However, data on the influence of bone marrow derived cells (BMDC, also called bone stromal cells in some publications) on lung cancer cells is largely unexplored. This study explored the mechanism of how bone stromal factors contribute to the bone tropism in lung cancer. The difference among lung cancer cell lines in their abilities to metastasize to bone was found using the SCID animal model. Supernatant of bone marrow aspiration (BM) and condition medium from human bone stromal cells (BSC) were used to study the activity of bone stromal factors. We found bone stromal factors significantly increased the proliferation, invasion, adhesion and expression of angiogenosis-related factors, and inhibited the apoptosis for high bone metastasis H460 lung cancer cells. These biologic effects were not seen in SPC-A1 or A549 cells, which are low bone metastasis lung cancer cells. Adhesion of H460 cells to surface coated with bone stromal cells can activate some signal transduction pathways, and alter the expression of adhesion associated factors, including integrin $\beta 3$ and ADAMTS-1, two potential targets related with bone metastasis. We concluded that bone marrow derived cells had a profound effect on biological
\end{abstract}

Correspondence to: Professor Shun Lu, Shanghai Lung Cancer Center, Shanghai Chest Hospital, Jiao Tong University, Shanghai 200030, P.R. China

E-mail: shun_lu1964@hotmail.com

Professor Hai-Quan Chen, Department of Thoracic Surgery, Shanghai Cancer Hospital, Fudan University, Shanghai 200032, P.R. China

E-mail: hqchen1@yahoo.com

*Contributed equally

Key words: bone stromal cells, lung cancer, biologic behavior behavior of lung cancers, therefore favoring the growth of lung cancer cells in bone.

\section{Introduction}

Bone is composed of different cell types in varying ratios, including osteoblastic cells, osteoclastic cells, bone stromal cells and endothelia cells. Bone seems a milieu particularly favorable for the growth, vascularization and survival of lung, breast and prostate cancer cells, but not colon or gastric cancer cells $(1,2)$. Disseminated cancer cells may initially require local nutrients and growth factors to thrive and survive in bone marrow (3). Bone marrow derived cells (BMDC), also called bone stromal cells, can secrete many growth factors and cytokines. The lists include, but are not limited to TGF- $\beta$, HGF, IL-6, CXCR4, GM-CSF, and GCSF (4-6).

Extra-cellular matrix (ECM) in the bone is rich in fibronectin, laminin, osteopontin and collagen. Before growing in the bone microenvironment, circulating tumor cells must adhere to extra-cellular matrix, and invade the interstitial space of the target organs, which is essential for development of bone metastasis. Therefore, it is postulated adhesion effect plays an important role for the bone tropism of cancer (7-9).

Malignant cells express molecular pathways that are probably also expressed by bone marrow derived cells. This Tumor-cell fusion is a source of myeloid traits in cancer, and a unifying explanation for bone metastasis $(10,11)$. There have been some studies specifically looking at the interaction between endothelia/osteoblastic/osteoclastic cells and cancer cells $(12,13)$. Recently, Idboufker et al reported osteoblastlike cells increased bone related gene expression (RANKL and PTHrP) and invasive gene (MMP-2) in breast cancer cells. Thus, osteoblast can modulate the ability of breast cancer to invade the bone matrix and to adapt to the bone microenvironment (14). However, data on the influence of bone stromal cells on lung cancer cells is largely unexplored. In order to explore the mechanism of how bone stromal factors contribute to the bone tropism, we use supernatant of bone marrow aspiration (BM) and condition medium from human 
bone stromal cells (BSC) to investigate their effects on lung cancer cells.

\section{Materials and methods}

Cell lines and reagents. Lung cancer cell lines, A549, H460, gastric cancer cell line SGC-7901 were obtained originally from ATCC. SPC-A1 lung cancer cell line, and tongue cancer cell line T8113 were already established in our laboratory and have been reported previously. These cells were cultured in pheno-red-free RPMI-1640/10\% fetal calf serum. Supernatant of bone marrow aspiration (BM) and condition medium from human bone stromal cells (BSC) were used to study the activity of bone stromal factors. Bone marrow samples $(10 \mathrm{ml})$ were obtained from the sternum intraoperatively, and stored in a tube with heparin, centrifuged at $2000 \mathrm{x} g$ for $10 \mathrm{~min}$ to separate plasma, which was stored at $-80^{\circ} \mathrm{C}$ until use. We did not dialyze BM. Supernatant was diluted 1:5 by regular medium for treatment. Human bone marrow derived cells (or human bone stromal cells) were purchased from Sciencell Research Laboratories (Cat. No.7500, Carlsbad, CA). Regular medium (RM), condition medium from fibroblast cells (FC) were chosen as controls.

MTT assay. MTT assay was applied to analyze these different treatments on proliferation of lung cancer cells and controls. Cells $\left(5 \times 10^{4} / \mathrm{ml}\right)$ were seeded on 96 -well plate on D0 in triplicate manner, and treated by RM, BSC, BM consecutively for 7 days. Every other day, medium was changed and OD was measured using MTT.

PI staining for cell cycle analysis. Flow cytometry analysis of DNA content was performed to assess the cell cycle phase distribution. Cells were harvested and stained for DNA content using propidium iodide fluorescence. The computer program Multicycle from Phenix Flow System (San Diego, CA) was used to generate histograms, which were used to determine the cell cycle phase distribution.

Apoptosis assay by double staining with annexin V-FITC and propidium iodide. Double staining of annexin V-FITC and propidium iodide (PI) were conducted according to manufacturer's instruction (Alexis Biochemicals, San Diego, $\mathrm{CA}$ ). In brief, $5 \times 10^{5}$ cells were rinsed with $1 \mathrm{X}$ binding buffer provided by kit, stained with $5 \mu \mathrm{l}$ annexin $\mathrm{V}(20 \mu \mathrm{g} / \mathrm{ml}$ in Tris- $\mathrm{NaCl})$ and $10 \mu \mathrm{l} \mathrm{PI}(50 \mu \mathrm{g} / \mathrm{ml}$ in $1 \mathrm{X}$ binding buffer $)$ in triplicate manner. After incubation at room temperature for $10 \mathrm{~min}$, the cells were immediately analyzed in a FACScan (Becton-Dickinson, San Jose, USA). Ten thousand cells were gated for analysis on the basis of forward and side scatter using FACscan software, and compensation values were adjusted according to annexin $\mathrm{V}$ alone and PI staining alone. Annexin ${ }^{+} / \mathrm{PI}^{-}$stands for early apoptosis and annexin ${ }^{+} / \mathrm{PI}^{+}$stands for late apoptosis/secondary necrosis.

Adhesion assay. Ninety-six cell tissue culture plates were coated with $\mathrm{RM}$ or $\mathrm{BM}$ at $37^{\circ} \mathrm{C}$ overnight. Cells were trypsinized and resuspended in RPMI-1640/0.1\% BSA at concentration of $5 \times 10^{5} / \mathrm{ml}$. After adhesion for $1 \mathrm{~h}$, the suspended cells were gently washed away by PBS. MTT was used to evaluate the quantity of cells remaining on the plate.
Real-time PCR. Real-time PCR was used to analyze expression of angiogenesis related factors induced by BM/BSC in H460 cells. Total RNA was extracted from two independent experiments by TRIzol reagent (Life Technologies, Inc., Rockville, MD) according to the manufacture's instructions. The first strand cDNA was synthesized with Superscript II reverse transcriptase and oligo(dT) primers. The primers were designed to span different exons to avoid amplification of genomic DNA. Real-time PCR was done in triplicate in a final volume of $10 \mu \mathrm{l}$ containing $0.1 \mu \mathrm{l}$ forward primer (10 ng/ $\mathrm{ml}), 0.1 \mu 1$ reverse primer, 0.1 $\mu \mathrm{l}$ SYBRA Green, $4.7 \mu 1 \mathrm{Mix}$ (Applied Biosystems, Foster City, CA). ABI 7900 sequence detector (Applied Biosystems) and SDS 2.2 software were used for PCR reaction and data analysis. Cycle threshold numbers $(\mathrm{Ct})$ of all genes were normalized to $ß$-actin. Samples without template were set up to exclude the measurement of primer dimers.

The following primers were designed: IL-8: upstream TTGGCAGCCTTCCTGATTTC, downstream TTAGCACT CCTTGGCAAAACTG; VEGF: upstream CACCATGCAG ATTATGCGGA, downstream CATCTCTCCTATGTGCT GGCCT; PDGF: upstream AAGGTGGCCAAGGTGGA ATAC, downstream TCCAAATGCTCCTCTAACCTCAC.

Microarray procedures. We used the Affymetrix gene chip U133A 2.0 to study the gene expression profile of H460 cells, after exposure to secreted proteins from bone stromal cells. Experiments were conducted in triplicate manner at 2 and $24 \mathrm{~h}$ time-points. Total RNA of the samples were isolated as described previously and further purified with RNeasy Mini kit (Qiagen, Valencia, CA), The cRNA labeling was performed according to protocols from Affymetrix, Inc. (Santa Clara, CA). The labeled cRNA was subsequently hybridized to human U133 133 A 2.0 oligonucleotide probe array (Affymetrix, Inc.) according to standard protocols done by Shanghai Biochip Co. Gene expression was considered to be significantly changed when 2-fold or more difference was detected and $\mathrm{P}<0.05$, calculated by $\mathrm{t}$-test between different time-points.

Some genes were selected for real-time PCR analysis to confirm microarray data. Real-time PCR was conducted as above. The following primers were designed: ADRb2: upstream 5'-GATTGCCTTCCAGGAGCTTCT-3', downstream 5'-CCATTCCCATAGGCCTTCAA-3'; BIRC3: upstream 5'-TGGTTTCCAAGGTGTGAGTACTTG-3', downstream 5'-AACTTGACGGATGAACTCCTGTC-3'; ADAMTS1: upstream 5'-TTTTGCAGCCCAAGGTTGTAG-3', downstream 5'-GATGCGATCACAACCAGCTTT-3'.

Invasion assay. Matrigel was diluted by pheno-free RPMI1640 to the concentration of $8.9 \% \mathrm{mg} / \mathrm{ml}$ on the ice. Cell culture inserts, $8.0 \mu \mathrm{mm}$ pore size (Becton-Dickinson Labware, Franklin Lakes, $\mathrm{NJ}$ ) were covered with Matrigel at $37^{\circ} \mathrm{C}$, and placed into 24 -well plates. Cells $\left(10^{6}\right)$ were added to the upper chamber of inserts, and regular medium/BM to the lower chamber. After $48 \mathrm{~h}$, cell culture inserts were fixed with $3.7 \%$ paraformaldehyde/PBS for $15 \mathrm{~min}$. Cells in the upper chamber were then removed with a cotton swab and the filters stained using a Diff-Quick stain (HEMA- $3^{\circledR}$ stain set, Biochemical Sciences, Swedesbord, NJ). Cells in 3 represen- 

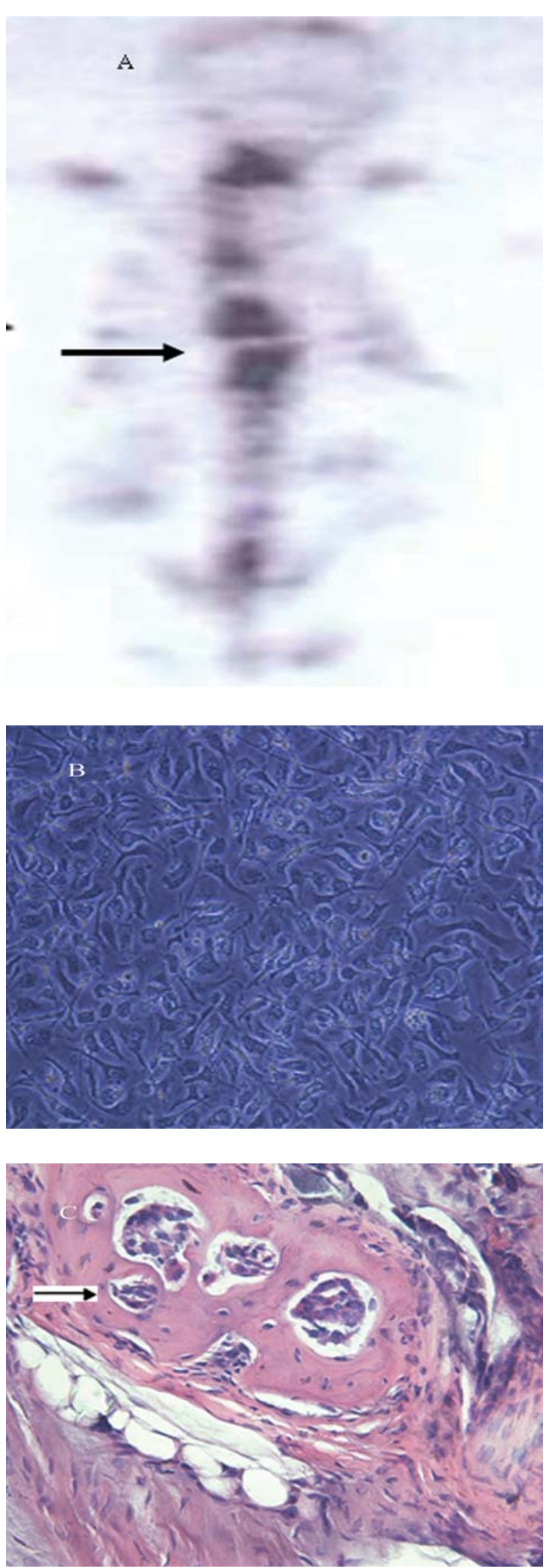

Figure 1. Bone metastasis of nude mice injected by H460. (A) SCID was injected with $\mathrm{H} 460$ cells through the tail vein. Eight weeks later, hot spot was detected by bone scan. (B) Tissues from spine were spliced and cultured, and cancerous cells were found. (C) Bone metastasis was confirmed further by pathological examination. tative x200 microscopic fields were counted. Invading ratio was defined as invading cells in control group divided by that in BM group. Assays were repeated 2 times with similar results.

Evaluation of bone metastasis potential of different lung cancer cell lines using bone scan and pathological examination. Different cell lines were injected into NIHBNX nude mice via tailor vein. Animal experimentation was in accordance with institutional guidelines. Bone metastasis was evaluated with bone scan 8 weeks after cell injection. Before dissection, $148 \mathrm{MBq}$ 99Tc-MDP 3mCo 99mTc-MDP (Shanghai Xinke Co., Shanghai) was injected into the mice, and bone scan using SPECTE was performed to ascertain the overall distribution of the radio-tracer. Bone metastasis was defined when hot spots were detected. To confirm these hot spots were real bone metastasis, bone tissues from specious areas were biopsied, sliced, and primary cell culture was conducted. Additionally, part of bone-metastasis-suspicious lesions were infiltrated into a $10 \%$ solution of formalin immediately, and delivered for the pathologic procedure within $24 \mathrm{~h}$. Section $4-\mu \mathrm{m}$ thick was cut for routing HE staining.

\section{Results}

The difference among lung cancer cell lines in ability to metastasize to bone. SCID was injected with lung cancer cells through tail vein. Eight weeks later, hot spots were detected by bone scan in all three mice injected with $\mathrm{H} 460$ cells (Fig. 1A). Tissues from specious spine were then sliced, and cancerous cells through primary culture indicated the bone contained metastasis (Fig. 1B). Additionally, bone metastasis was also confirmed by pathological examination. So $\mathrm{H} 460$ cells have high bone metastasis potential shown by our nude mice model. This result was consistent with report by Yang et al (15). With a similar experiment we found one out of 9 mice with SPC-A1 cells, and one out of 10 mice injected with A549 developed bone metastasis. Our results showed SPC-A1 and A549 cells are low bone metastasis lung cancer cells, in accordance with literature reports $(16,17)$.

Bone stromal factors promoted proliferation of lung cancer cells with high bone metastasis potential. Both supernatants from BM and BSC significantly increased the proliferation of H460 lung cancer cells, which had wide-spread skeletal metastatic potential shown in the above animal experiment (Fig. 2A). This activity was not shown in A549 and SPC-A1 lung caner cells (Fig. 2B and C). BM did not improve the proliferation of tongue cancer cells T8113, which had very low bone metastasis potential, and even inhibited the growth of SGC7901, a gastric cancer cell line with rare metastasis to bone (Fig. 2D and E). Bone stromal-cell-induced proliferation in H460 cells was blocked by Zometa (bisphosphonate), but not by PI3-K inhibitor Wartmannin in time-course and dose-dependent studies (Fig. 2F).

Flow cytometry analysis showed that both BM and BSC reduced early and late apoptosis in H460 cells (Fig. 3), but did not affect cell cycle distribution. It could be the underlying mechanism by which BM and BSC promoted H460 cells proliferation. In the low bone metastasis lung cancer 
A

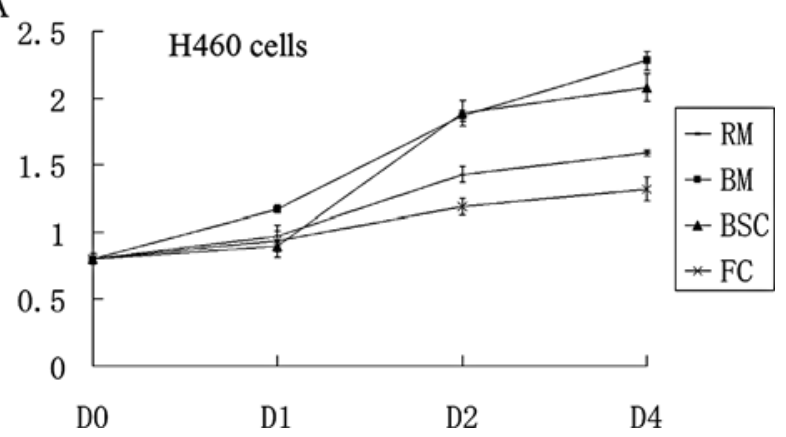

C

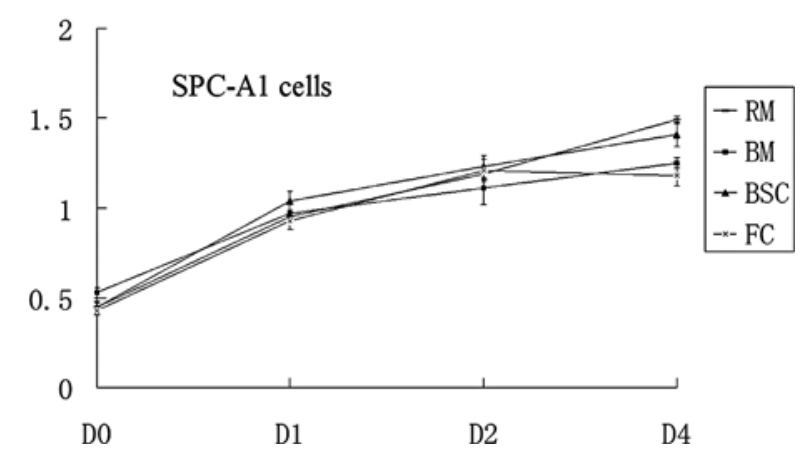

cells SPC-A1, neither BM nor BSC affected its apoptosis and cell cycle distribution (data not shown).

Bone stromal factors promote adhesion, invasion and expression of angiogenesis associated factors in lung cancer cells with high bone metastasis potential. We investigated whether different bone metastasis potential of cell lines was related to their adhesive capability to bone stromal cells. Through adhesion assay, we found $\mathrm{H} 460$ cells were more likely to adhere to the plates coated by supernatant from bone stromal cells than regular medium. In contrast, SPC-A1 cells showed equivalent adhesive capability to supernatant from bone stromal cells and regular medium (Fig. 4A).

Invasive capability was closely associated with bone metastasis potential. Differences between lung cancer cell lines were also tested by invasion assay. There were significantly more $\mathrm{H} 460$ cells, which invaded through Matrigel to BM compared with $(\mathrm{P}=0.001)$. In the low bone metastasis

B

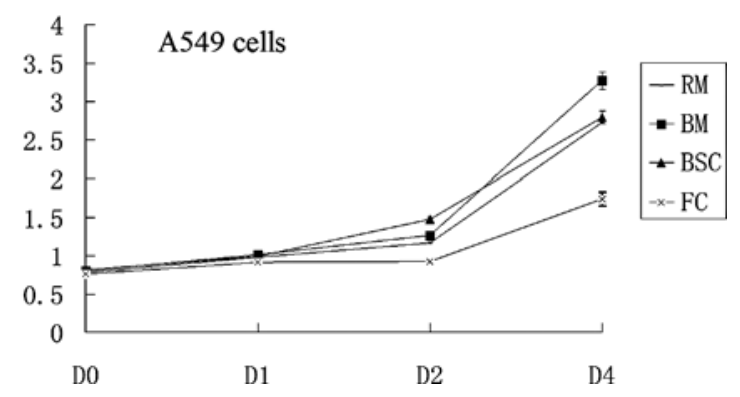

D

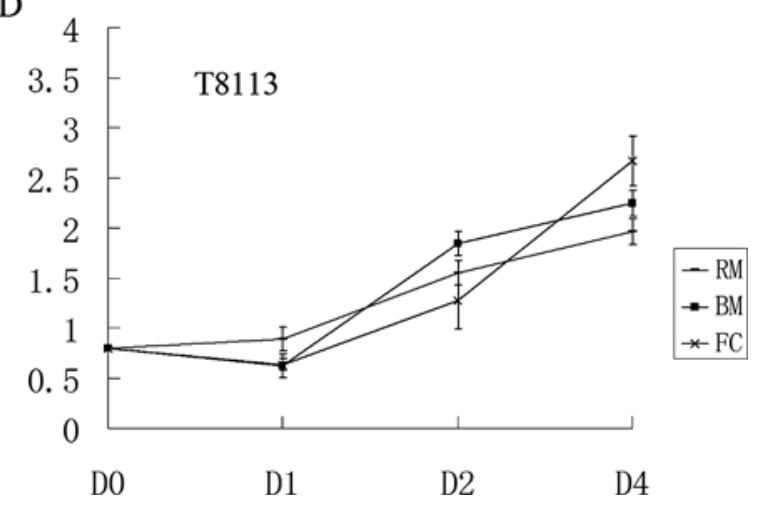

Figure 2. The effect of BM and BSC on the proliferation of H460 lung cancer cells (A), A549 lung cancer cells (B), SPC-A1 lung cancer cells (C), T8113 tongue cancer cells (D) and gastric cancer cells (E). (F) Bonestromal-cell-induced proliferation in $\mathrm{H} 460$ cells was blocked by Zometa (biphosphanate), but not by PI3-K inhibitor Wartmannin.

cells, for both SPC-A1 and A549, there was no apparent difference in the invasion ratio between $\mathrm{BM}$ and $\mathrm{RM}(\mathrm{P}>0.05)$ (Fig. 4B and C).

Disseminated tumor cells cannot grow within bone without a supply of new blood vessels. Our real-time PCR showed both BM and BSC increased the expression of proangiogenic factors, PDGF and IL-8, after $24 \mathrm{~h}$ of treatment (Fig. 5).

Exposure to bone stromal proteins may activate downstream signaling in $\mathrm{H} 460$ cells. Secreted protein from bone stromal cells might facilitate the homing of tumor cells. After adhering to the plate coated with the condition medium from bone stromal cells for $2 \mathrm{~h}, 97$ genes were significantly up-regulated. Analysis using Ontoexpress software indicated these genes were associated with protein and amino acid biosynthesis. After adhering for $24 \mathrm{~h}, 145$ genes were significantly upregulated, these are associated with signal transduction, cell adhesion and regulation of transcription.

Microarray showed a total of 31 genes that were consistently up-regulated in $\mathrm{H} 460$ cells (Table I). Some of these genes, including ADAMTS1, BIRC3, were confirmed by real-time PCR. Ontoexpress showed that the main function of the 31 genes were associated with signal transduction pathways (5 genes) and adhesion molecules (5 genes). Our study showed adhesion of $\mathrm{H} 460$ cells to bone stromal cells can activate some signal transduction pathways and alter the expression of adhesion associated factors, and thus favoring 
A

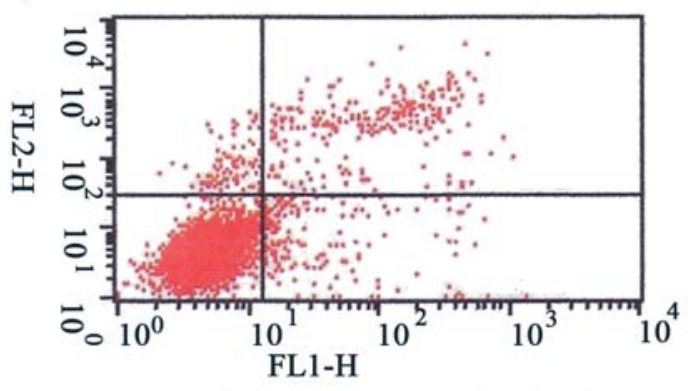

B

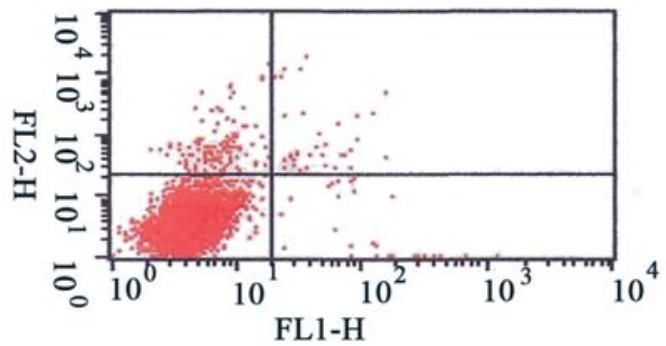

C

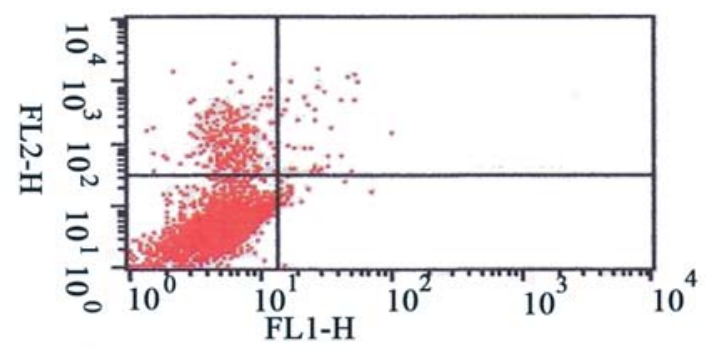

Figure 3. Double staining of Annexin V-FITC and propidium iodide (PI) to examine apoptosis in $\mathrm{H} 460$ cells (A) $24 \mathrm{~h}$ after the treatment of regular medium, (B) $24 \mathrm{~h}$ after the treatment of condition medium from human bone stromal cells, (C) $24 \mathrm{~h}$ after the treatment of supernatant of bone marrow. $\mathrm{x}$-axis, annexin $\mathrm{V}$ staining and $\mathrm{y}$-axis, PI staining; $\mathrm{PI}^{-} /$annexin $\mathrm{V}^{+}$early apoptosis and $\mathrm{PI}^{+}$/annexin $\mathrm{V}^{+}$late apoptosis. Compared with $\mathrm{RM}$ treatment, percentage of both early apoptosis ( $\mathrm{PI}^{-} /$annexin $\mathrm{V}^{+}, 1.08 \pm 0.47$ and $3.17 \pm 0.06, \mathrm{P}=0.0015)$ and late apoptosis/ secondary necrosis $\left(\mathrm{PI}^{+} /\right.$annexin $\mathrm{V}^{+}, 0.827 \pm 0.215$ and $\left.2.11 \pm 0.36, \mathrm{P}=0.0061\right)$ in $\mathrm{BM}$ group was significantly less. Similarly, after treatment of BSC, both early apoptosis $(0.7 \pm 0.31$ and $3.17 \pm 0.06, \mathrm{P}=0.0068)$ and late apoptosis/secondary necrosis $(0.497 \pm 0.08$ and $2.11 \pm 0.361, \mathrm{P}=0.0001$ ) were also decreased.

the growth of cancer cells with high potential for bone metastasis.

\section{Discussion}

Bone metastasis occurs in about $20 \%$ of patients and causes pain and detrimental complications including spinal cord compression and pathologic fracture $(18,19)$. Consensus recommendations of the second Cambridge conference in 2008 (20) indicated that one of the priorities that needs further study and should be a major focus of research within the next five years is, modulation of the effects of bone cells on other cell types and their interactions with the bone microenvironment. The purpose of this current study is to
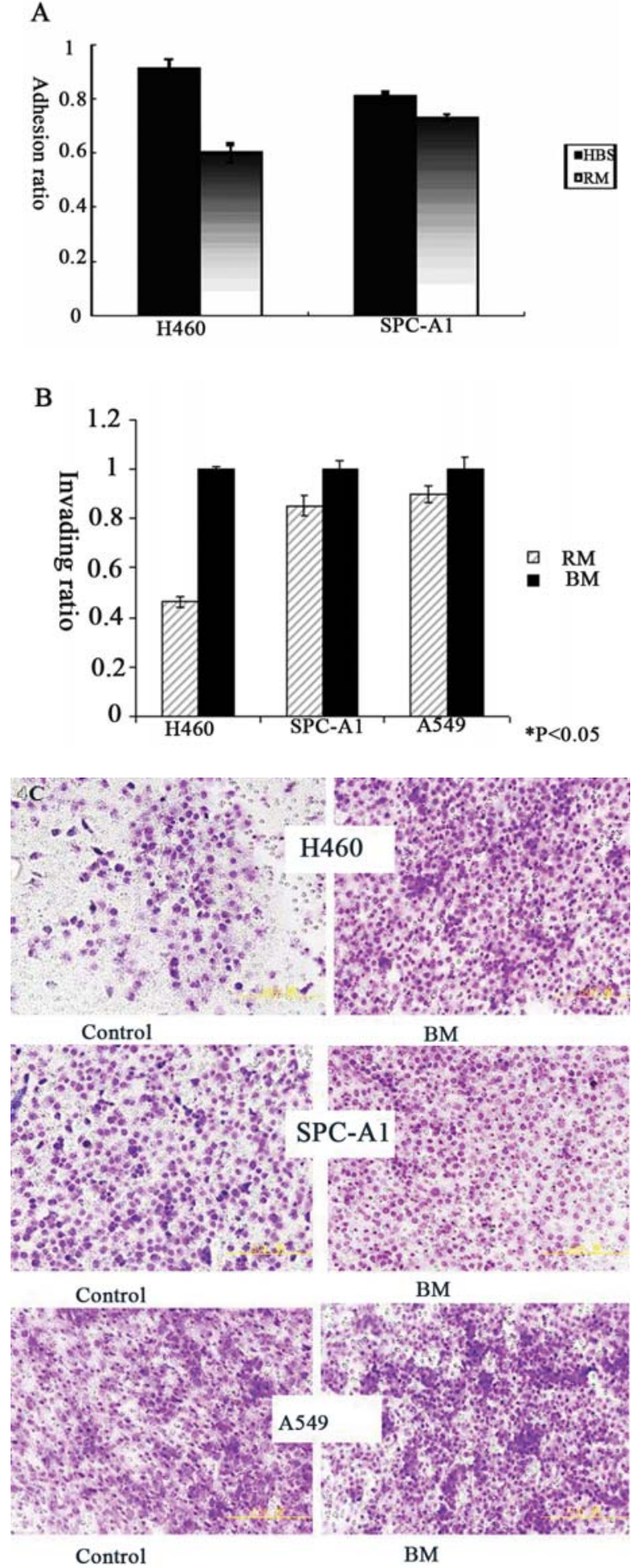

Figure 4. (A) Different bone metastasis potential of cell lines was related to their adhesive capability to bone stromal cells. The plates were coated by either supernatant from bone stromal cells or regular medium. The adhesion ratio was defined as remaining cells after adhesion for $1 \mathrm{~h}$ compared by total cell number. HBS, human bone stromal cell. (B) Difference among lung cancer cell lines shown by invasion assay. Invading ratio was defined as invading cells in control group divided by that in BM group. Assays were conducted in triplicates, and mean/SD is presented. ${ }^{*} \mathrm{P}<0.05$. (C) Cell culture inserts were fixed with $3.7 \%$ paraformaldehyde/PBS for $15 \mathrm{~min}$ and were then stained using a Diff-Quick stain. Cells in 3 representative $\times 200$ microscopic fields were counted.

contribute to a better understanding of the interaction of tumor and bone microenvironment. 


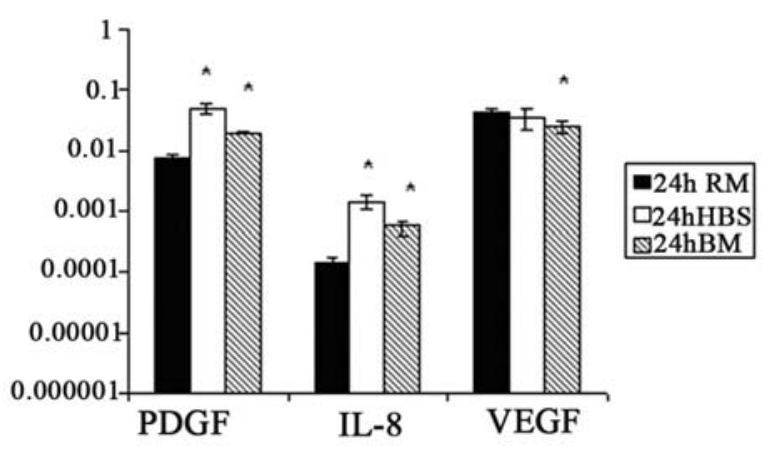

Figure 5. Real-time PCR was used to analyze the regulation of angiogenesis related factors for $\mathrm{H} 460$ after $24 \mathrm{~h}$ different treatments. Experiment was done in triplicate with SYBRA Green Master Mix. ABI 7900 sequence detector and SDS 2.0 software were used for PCR reaction and data analysis. $\mathrm{x}$-axis, different angiogenesis related factors and $\mathrm{y}$-axis, the relative values normalized to $\beta$-actin. ${ }^{*} \mathrm{P}<0.05$.
BMDC-tumor fusion has been detected in numerous animal models and recently in human cancer (11). Although a supporting role of bone stromal factors on metastatic breast or prostate cancer cells have been repeatedly proposed, it is largely unknown what the mechanism of bone tropism is for lung cancer. In our study, we found bone stromal factors favored the growth of cancer cells with bone tropism by increasing proliferation, reducing apoptosis, promoting angiogenesis, invading capability, but not affecting cell cycle. Bone stromal cells secrete some growth factors which promote the proliferation of high bone metastasis potential cells. Our hypothesis is supported by the finding that flt- 1 signaling in bone marrow derived cells was required for its activity on the growth of glioma (21).

Zometa has been proved to exert multiple biological effects, including inhibition of proliferation, cell adhesion

Table I. Up-regulated genes of H460 after adhering to the supernatants of bone stromal cells (increased $>2$-fold, $\mathrm{P}<0.05$ ).

\begin{tabular}{|c|c|c|c|c|}
\hline Gene title & Public ID & $\begin{array}{l}\text { Fold change } \\
2 \mathrm{~h} / 0 \mathrm{~h}\end{array}$ & $\begin{array}{l}\text { Fold change } \\
24 \mathrm{~h} / 2 \mathrm{~h}\end{array}$ & t-test \\
\hline CTP synthase & NM_001905 & 2.15 & 1.70 & 0.0002 \\
\hline Matrix metalloproteinase 7 & NM_002423 & 2.17 & 1.45 & 0.0002 \\
\hline HSD3B1 & NM_000862 & 5.38 & 1.24 & 0.0106 \\
\hline INPP4A & NM_004027 & 2.15 & 1.33 & 0.0464 \\
\hline Integrin $\beta 3$ & NM_000212 & 4.60 & 1.18 & 0.0374 \\
\hline FGF binding protein 1 & NM_005130 & 2.08 & 1.03 & 0.0002 \\
\hline Forkhead box J1 & NM_001454 & 2.18 & 1.16 & 0.0136 \\
\hline Adrenergic, $\beta-2-$, receptor, surface & NM_000024 & 2.03 & 1.22 & 0.0064 \\
\hline Calcium channel $\gamma$ subunit 1 (CACNG1) & NM_000727 & 2.32 & 1.47 & 0.0042 \\
\hline Jagged 1 & U73936 & 3.31 & 4.94 & 0.0063 \\
\hline Tissue factor pathway inhibitor 2 & L27624 & 2.08 & 2.32 & 0.0033 \\
\hline Phosphatidic acid phosphatase type $2 \mathrm{~B}$ & AB000889 & 2.03 & 1.11 & 0.0294 \\
\hline Adlican & AF245505 & 3.59 & 2.12 & 0.0194 \\
\hline Baculoviral IAP repeat-containing 3 & U37546 & 2.07 & 3.36 & 0.0249 \\
\hline Flavoprotein oxidoreductase MICAL2 & BE965029 & 2.31 & 1.39 & 0.0055 \\
\hline TNF receptor superfamily, member 21 & BE568134 & 3.08 & 2.40 & 0.0021 \\
\hline HMT1 hnRNP methyltransferase-like 1 & AL050065 & 4.52 & 1.33 & 0.0309 \\
\hline Jagged 1 (Alagille syndrome) & U77914 & 2.57 & 4.78 & 0.0410 \\
\hline Laminin $\alpha 2$ & AK026829 & 4.82 & 1.79 & 0.0244 \\
\hline PHLDA1 & NM_007350 & 3.03 & 3.25 & 0.0335 \\
\hline TNF receptor superfamily, member $12 \mathrm{~A}$ & NM_016639 & 2.06 & 1.90 & 0.0190 \\
\hline Chromosome 12 open reading frame 5 & NM_020375 & 2.85 & 1.12 & 0.0004 \\
\hline Lipase, endothelial & NM_006033 & 3.55 & 1.13 & 0.0121 \\
\hline Sphingosine kinase 1 & NM_021972 & 2.13 & 2.41 & 0.0008 \\
\hline Aldehyde dehydrogenase 8 family member A1 & NM_022568 & 6.51 & 1.32 & 0.0317 \\
\hline Heat shock $70 \mathrm{kDa}$ protein $12 \mathrm{~A}$ & NM_025015 & 2.02 & 2.67 & 0.0310 \\
\hline Syntaxin binding protein 6 (amisyn) & NM_014178 & 4.96 & 1.30 & 0.0175 \\
\hline ADAMTS-1 & AK023795 & 2.06 & 1.97 & 0.0010 \\
\hline SCAN domain containing 2 & AF244812 & 3.07 & 1.48 & 0.0301 \\
\hline Inter- $\alpha$ (globulin) inhibitor H4 & D38535 & 3.01 & 1.22 & 0.0472 \\
\hline Adenosylmethionine decarboxylase 1 & M21154 & 2.02 & 1.06 & 0.0007 \\
\hline
\end{tabular}


and matrix invasion of tumor cells, and increasing apoptosis. The mechanism of its effect is to inhibit farnesyl diphosphate synthase, thus blocking the prenylation of small signaling proteins essential for cell function and survival. In our study, we found Zometa inhibited the proliferation-promoting activity of BM. We are going to use cytokine array to investigate its molecular pathway.

The pathways of metastasis have been under intense scientific scrutiny and much is now known about the steps involved. However, the actual genes involved in bone metastasis are not fully understood. Integrin anchors on ECM and may secondarily trigger the downstream signaling. Its role in mediating bone metastasis has been repeatedly investigated $(22,23)$. Prostate cancer cells selected in vitro for collagen I binding (LNCaPcol) are highly motile and acquired the capacity to grow within the bone compared to nontumorigenic $\mathrm{LNCaP}$ parental cells. The expression of integrin $\alpha 2 \beta 1$, RhoC guanosine triphosphatase was increased in high bone metastasis, collagen-binding LNCaPcol and C4-2B cells, compared to parental LNCaP cells $(24,25)$. Integrin avB3 was associated with breast cancer bone metastasis, and its inhibition by $\mathrm{S} 247$ can reduce bone metastasis (26-28). Our study showed adhesion of H460 cells to bone stromal cells can activate some signal transduction pathways, and alter the expression of adhesion associated factors, therefore favoring the growth of cancer cells with high bone metastasis potential. One of the increased genes, integrin $\beta 3$, is a member of integrin family. Lung cancer variably expressed integrin $\alpha \mathrm{v} \beta 3$ and there was no data on its expression in metastatic lung cancer in the bone (29). So the role of $\beta 3$ integrin in bone metastasis of lung cancer needs to be further verified.

Another interesting gene is ADAMTS-1 (a disintegrin and metalloprotease with thrombospondin type I motifs), one of the 19 members of a family of genes for metalloproteinase. It is located at chromosome $16 \mathrm{C} 3-5$ region in mice and at chromosome 21 in human. It comprises of 6 regions: prometalloproteinase, metalloproteinase, disintegrin-like region, TSP-I thrombospondin, homologous domain containing TSP type I motif, spacer region and TSPCOOH-terminal TSP submotifs (30). Liu et al reported the role of ADAMTS-1 in lung metastasis from SCID models injected with breast and lung cancer cell lines (31). Rock et al compared the ADAMTS-1 expression of lung cancer with surrounding normal tissue and found higher expression in tumor cells (32). Parathyroid hormone (PTH) was able to up-regulate ADAMTS-1 expression and increase osteoblastic activities via the type I collagen processing (33), indicating the active role of ADAMTS-1 in bone microenviroment. We are presently verifying if ADAMTS-1 could be associated with bone metastasis.

\section{Acknowledgements}

This study is supported, in part, by National Natural Science Foundation of China 30800404, Shanghai Rising-Star Program (09QA1401200) Young investigator grant from Department of Education in China, IBS Bio-Medicine Grant, (to J.Z.), Shanghai Leading Academic Discipline Project (B115), Shanghai Municipal Natural Science Fund (06DZ19503) and Basic-Clinical Medicine Grant (H.-Q.C.).

\section{References}

1. Kang Y, Siegel P and Shu W: A multigenic program mediating breast cancer metastasis to bone. Cancer Cell 3: 537-549, 2003.

2. Kaplan RN, Riba RD and Zacharoulis S: VEGFR1-positive haematopoietic bone marrow progenitors initiate the premetastatic niche. Nature 438: 820-827, 2005.

3. Mundy GR: Metastasis to bone: causes, consequences and therapeutic opportunities. Nat Rev Cancer 8: 584-593, 2002.

4. Powell GJ, Southby J and Danks JA: Localization of parathyroid hormone-related protein in breast cancer metastases: increased incidence in bone compared with other sites. Cancer Res 51: 3059-3061, 1991.

5. Yin JJ, Mohammad KS and Kakonen SM: A causal role for endothelin-1 in the pathogenesis of osteoblastic bone metastases. Proc Natl Acad Sci USA 100: 10954-10959, 2003.

6. Guise TA, Mohammad KS and Clines G: Basic mechanisms responsible for osteolytic and osteoblastic bone metastases. Clin Cancer Res 12: S6213-S6216, 2006.

7. Burridge K and Wennerberg K: Rho and Rac take center stage. Cell 116: 167-179, 2004

8. Hemler ME: VLA proteins in the integrin family, structures, functions and their role on leukocytes. Annu Rev Immunol 8: 365-400, 1990

9. Mattila E, Pellinen T and Nevo J: Integrins and EGFR coordinately regulate the pro-apoptotic protein Bim to prevent anoikis. Nat Cell Biol 5: 733-740, 2003.

10. Pawelek JM: Tumour-cell fusion as a source of myeloid traits in cancer. Lancet Oncol 6: 988-993, 2005.

11. Pawelek JM and Chakraborty AK: Fusion of tumour cells with bone marrow-derived cells: a unifying explanation for metastasis. Nat Rev Cancer 8: 377-386, 2008.

12. Gallagher PG, Bao Y and Prorock A: Gene expression profiling reveals cross-talk between melanoma and fibroblasts: implications for host-tumor interactions in metastasis. Cancer Res 65: 4134-4146, 2005.

13. Kaminski A, Hahne JC, Haddouti El-M, Florin A, Wellmann A and Wernert N: Tumour-stroma interactions between metastatic prostate cancer cells and fibroblasts. Int J Mol Med 18: 941-950, 2006.

14. Idboufker H, Lagneaux L and Tatiana L: Effects of osteoblastlike cells on bone-related and invasive gene expressions in breast cancer cells. Bone 42: S96, 2008.

15. Yang M, Hasegawa S and Jiang P: Widespread skeletal metastatic potential of human lung cancer revealed by green fluorescent protein expression. Cancer Res 58: 4217-4221, 1998.

16. Hastings RH, Burton DW, Summers-Torres D, Quintana R, Biederman E and Deftos LJ: Splenic, thymic, bony and lymph node metastases from orthotopic human lung carcinomas in immunocompromised mice. Anticancer Res 20: 3625-3629, 2000.

17. Lu S, Zhang J and Zhou Z: Synergistic inhibitory activity of zoledronate and paclitaxel on bone metastasis in nude mice. Oncol Rep 20: 581-587, 2008.

18. Roodman GD: Biology of osteoclast activation in cancer. J Clin Oncol 19: 3562-3571, 2001.

19. Roodman GD: Mechanisms of bone metastasis. N Engl J Med 350: 1655-1664, 2004.

20. Coleman RE, Guise TA and Lipton A: Advancing treatment for metastatic bone cancer: consensus recommendations from the Second Cambridge Conference. Clin Cancer Res 14: 6387-6395, 2008.

21. Kerber M, Reiss Y and Wickersheim A: Flt-1 signaling in macrophages promotes glioma growth in vivo. Cancer Res 68: 7342-7351, 2008

22. Matsuura N, Puzon-McLaughlin W, Irie A, Morikawa Y, Kakudo $\mathrm{K}$ and Takada Y: Induction of experimental bone metastasis in mice by transfection of integrin alpha 4 beta 1 into tumor cells. Am J Pathol 148: 55-61, 1996.

23. Hayashi C, Rittling S and Hayata T: Serum osteopontin, an enhancer of tumor metastasis to bone, promotes B16 melanoma cell migration. J Cell Biochem 101: 979-986, 2007.

24. Hall CL, Dubyk CW, Riesenberger TA, Shein D, Keller ET and van Golen KL: Type I collagen receptor $(\alpha 2,1)$ signaling promotes prostate cancer invasion through RhoC GTPase. Neoplasia 10: 797-803, 2008.

25. Hall CL, Dai J, van Golen KL, Keller ET and Long MW: Type I collagen receptor (alpha 2 beta 1) signaling promotes the growth of human prostate cancer cells within the bone. Cancer Res 66: $8648-8654,2006$ 
26. Harms JF, Welch DR and Samant RS: A small molecule antagonist of the alpha(v)beta3 integrin suppresses MDA-MB435 skeletal metastasis. Clin Exp Metastasis 21: 119-128, 2004.

27. Gomes N, Vassy J, Lebos C, Arbeille B, Legrand C and FauvelLafeve F: Breast adenocarcinoma cell adhesion to the vascular subendothelium in whole blood and under flow conditions: effects of alphavbeta3 and alphaIIbeta3 antagonists. Clin Exp Metastasis 21: 553-561, 2004

28. Schneider D, Liaw L and Daniel C: Inhibition of breast cancer cell adhesion and bone metastasis by the extracellular adherence protein of Staphylococcus aureus. Biochem Biophys Res Commun 357: 282-288, 2007.

29. Koukoulis GK, Warren WH, Virtanen I and Gould VE: Immunolocalization of integrins in the normal lung and in pulmonary carcinomas. Hum Pathol 28: 1018-1025, 1997.
30. Mochizuki S and Okada Y: ADAMs in cancer cell proliferation and progression. Cancer Sci 98: 621-628, 2007.

31. Liu YJ, Xu Y and Yu Q: Full-length ADAMTS-1 and the ADAMTS-1 fragments display pro- and antimetastatic activity, respectively. Oncogene 25: 2452-2467, 2006.

32. Rocks N, Paulissen G and Quesada Calvo F: Expression of a disintegrin and metalloprotease (ADAM and ADAMTS) enzymes in human non-small cell lung carcinomas (NSCLC). Br J Cancer 94: 724-730, 2006

33. Rehn AP, Birch MA, Karlström E, Wendel M and Lind T: ADAMTS-1 increases the three-dimensional growth of osteoblasts through type I collagen processing. Bone 41: 231-238, 2007. 